\title{
Dural Cavernous Angioma: A Preoperative Diagnostic Challenge
}

\author{
Dominic Rosso, Donald H. Lee, Gary G. Ferguson, Chetna Tailor, Sam Iskander, \\ Robert R. Hammond
}

\begin{abstract}
Background: Dural cavernous angiomas are uncommon benign vascular malformations which may present intraoperative difficulties in hemostasis when the diagnosis is not suspected preoperatively. Preoperative diagnosis can be difficult when angiomas show atypical features and share imaging characteristics with other entities. Methods: A patient presented with a radiographically aggressive lesion, subsequently identified as a dural cavernous angioma. The lesion is reviewed and its clinical, radiographic, and pathological features are compared with other vascular malformations. Case report: A 40-year-old man presented with new onset seizures and an enhancing lesion infiltrating the floor of the right middle cranial fossa. Due to its aggressive radiographic appearance, initial considerations included chondrosarcoma, meningioma or metastasis. Pathological examination, however, revealed the lesion to be a cavernous angioma of dura. Conclusion: This uncommon lesion may present a diagnostic challenge with significant intraoperative implications. T2 sequence hyperintensity in a relevant lesion should raise suspicion of an hemangioma. It is important to be aware of this entity and its potential to mimic other entities on radiographic grounds.
\end{abstract}

RÉSUMÉ: Les angiomes caverneux de la dure-mère: un défi diagnostique préopératoire. Introduction: Les angiomes caverneux de la dure-mère sont des malformations vasculaires bénignes rares. L'hémostase peut faire problème au moment de la chirurgie si le diagnostic n'a pas été envisagé avant la chirurgie. Le diagnostic préopératoire peut être difficile à poser quand l'angiome présente des caractéristiques atypiques communes à d'autres pathologies. Méthodes: Il s'agit d'une lésion d'aspect agressif à la radiologie chez un patient chez qui on a éventuellement posé un diagnostic d'angiome caverneux de la dure-mère. Nous décrivons la lésion et nous comparons ses caractéristiques cliniques, radiologiques et anatomopathologiques à celles d'autres malformations vasculaires. Étude de cas: Un homme âgé de 40 ans a consulté pour des crises convulsives d'apparition récente. L'évaluation a montré la présence d'une lésion rehaussante infiltrant le plancher de la fosse cérébrale moyenne droite. Vu son aspect radiologique agressif, on a considéré la possibilité qu'il s'agisse d'un chondrosarcome, d'un méningiome ou de métastases. L'examen anatomopathologique a révélé qu'il s'agissait d'un angiome caverneux de la dure-mère. Conclusions: Cette pathologie rare peut présenter un défi diagnostique comportant des incidences opératoires importantes. Une hyperintensité sur la séquence pondérée en T2 au niveau de ce type de lésion devrait faire soupçonner la présence d'un hémangiome. Il est important de connaître les caractéristiques de cette pathologie et de garder à l'esprit que son aspect radiologique peut prêter à confusion.

Can. J. Neurol. Sci. 2003; 30: 272-277

Cavernous angiomas are benign vascular hamartomas consisting of abnormally dilated, thin-walled, vascular channels lacking an elastic lamina and mural smooth muscle. They are lined by a single layer of endothelium and possess intervening fibrous connective tissue. ${ }^{1}$ Cavernous angiomas account for approximately $10 \%$ of cerebral vascular malformations and can occur anywhere in the central nervous system. Dural cavernous angiomas are relatively rare with most occurring in the middle cranial fossa. ${ }^{2}$ Preoperative radiological investigations often suggest the diagnosis of meningioma with homogeneous enhancement of an extra-axial dural-based mass. ${ }^{3}$ Surgical intervention on an unsuspected dural cavernous hemangioma often results in uncontrollable hemorrhage. ${ }^{4}$

We report a case of a 40 -year-old man presenting with an enhancing lesion involving the floor of the right middle cranial

From the Departments of Clinical Neurological Sciences (DR ,DHL, GGF, RRH), Diagnostic Radiology (DR, DHL) and Pathology (CT, SI, RRH), London Health Sciences Centre, University of Western Ontario, London, ON Canada.

ReCeived SePtember 5, 2002. ACCEPTED in final form February 26, 2003. Reprint requests to: Robert R. Hammond, Department of Pathology, LHSC-UC, 339 Windermere Road, PO Box 5339, London, ON, Canada N6A 5A5. 
fossa. its aggressive appearance on imaging led to initial considerations of chondrosarcoma, meningioma with bony infiltration, and metastasis. Intraoperatively it bled profusely. Pathological investigation identified the lesion as a cavernous angioma. This case stresses the importance of being aware of this entity, recognizing that dural cavernous angiomas can masquerade as meningiomas or more aggressive tumours.

\section{CASE Report}

A 40-year-old right-handed man presented with a history of new onset generalized seizures. His first episode took place 10 weeks prior to admission. He had been sleeping when family members described finding him in a generalized tonic-clonic seizure. A second seizure took place three weeks prior to admission while the patient was rising from a chair. He fell to the floor and proceeded to have another generalized tonic-clonic event. The patient was placed on Dilantin and had no further episodes.

A CT and MRI identified a $3 \mathrm{~cm}$ heterogeneously enhancing mass involving the floor of the right middle cranial fossa (Figure 1) where it extended into right temporal bone and through the skull base. It showed irregular destruction of the temporal bone and extended to the temporomandibular joint. T2 signaling was heterogeneous within the mass but largely hyperintense with respect to brain. Collectively, the radiographic features suggested an aggressive lesion and chondrosarcoma was felt to be the most likely diagnosis. Other differential diagnoses considered were an aggressive meningioma and a metastasis.

He was taken to the operating room where a right pterional craniotomy was performed. Exploration of the right middle fossa revealed a moderately vascular, extra-axial lesion. It was well demarcated from the brain and appeared to have a capsule that was contiguous with the dura of the floor of the middle fossa. During resection of the tumour there was brisk bleeding attesting to its vascularity. The tumour was also firmly attached to the skull base over an area of approximately $2 \times 3 \mathrm{~cm}$. Removal of the bulk of the tumour revealed deeper infiltration of the skull base by several pockets of tumour. Gross total removal of the latter was achieved using an ultrasonic surgical aspirator and a high speed diamond drill. The bone of the infiltrated skull base was sclerotic.

The lesion had a lobulated whitish encapsulated surface, while the internal structure was spongy and reddish-brown. Microscopically, the specimen was a highly vascular paucicellular lesion (Figure 2). The component vessels were thin-walled sinusoidal channels lined by a single layer of endothelium. The vessels lacked any identifiable media or internal elastic lamina. The scanty interstitium was sparsely populated by benign appearing spindle cells. Cell borders were indistinct and the nuclei ranged from round to oval with dispersed chromatin. Immunohistochemistry with Ulex europeus lectin and anti-Factor VIII revealed strong expression of these endothelial cell antigens (Figure 2) leading to a final diagnosis of dural cavernous angioma.

\section{DiscuSsion}

Cavernous angiomas (cavernomas) are benign vascular malformations considered to arise secondary to failure of normal embryonic vascular development, thereby explaining their occurance in newborns. Cavernomas are most often parenchymal lesions and their enlargement may be secondary to a number of factors including thrombosis, engorgement, recruitment of adjacent feeding vessels, episodes of perilesional hemorrhage and hormonal influences. ${ }^{5}$ Although uncommon, cavernomas have previously been identified in the dura; with two such cases reporting spontaneous hemorrhage. ${ }^{5}$

The locational differences between parenchymal and the rarer dural cavernomas accounts for their differing clinical presentations and warrants their separate grouping. Furthermore, dural cavernomas arguably deserve subclassification based on their location, clinical expression and treatment considerations. Most commonly they are found in the middle cranial fossa, ${ }^{5}$ in a parasellar location. Other sites include the anterior fossa, falx, convexity, tentorium and internal auditory canal. The illustrative case is one of a nonparasellar middle fossa lesion in a 40-yearold male presenting with seizures.

Parenchymal cavernomas represent approximately $10 \%$ of all cerebrovascular malformations in autopsy studies and are believed to have a general population prevalence of 0.5 to $0.7 \%$. $^{6}$ The vast majority are sporadic with $15 \%$ showing multiple lesions. ${ }^{1,6}$ A familial autosomal dominant form is also recognized, with $75 \%$ showing multiple lesions. The majority are hemispheric and most commonly superficial in close contact with the subarachnoid space or ventricular system. Deep hemispheric involvement (ganglionic, diencephalic) is seen in $10 \%$, but they have been described throughout the CNS with $25 \%$ being infratentorial. ${ }^{7}$

Dural cavernous angiomas are unusual lesions by comparison and appear to exist in two demographic and anatomical distributions. The majority have been found in the middle cranial fossa in a parasellar location with 86\% (32/37) arising in females, chiefly in the fourth to sixth decades. ${ }^{8}$ Sixty-eight percent of all such cases were Japanese. ${ }^{8}$ The remainder have no age, gender or cultural predilection. ${ }^{5}$ To date, no familial tendency has been identified, but a single case of multiple lesions has been reported. ${ }^{5}$

Parenchymal cavernomas are often asymptomatic, being found incidentally in $0.4 \%$ of MRI examinations. Overall, seizures are the most common presentation, especially in patients less than 40 years old. Posterior fossa lesions often present with a focal neurologic deficit. Spontaneous hemorrhage is a known risk, estimated at approximately $1 \%$ per lesion per year in familial forms and $0.5-1 \%$ per lesion per year in the sporadic variety. ${ }^{9}$ Porter et $\mathrm{al}^{10}$ recently reviewed the clinical features of intra-axial cavernomas and their relationship to hemorrhage and concluded that deep lesions were more likely to produce clinically significant events.

The dural cavernomas have a varied clinical presentation predominantly based on their location (Table 1). Due to their intimate association with the cavernous sinus, anterior clinoid process and superior orbital fissure, parasellar examples typically present with ocular manifestations. Symptoms noted include visual disturbances such as diplopia, visual field defects and exophthalmos. ${ }^{4,8,11}$ Involvement of the fifth cranial nerve accounts for reported facial sensory deficits. ${ }^{8}$ The time course of symptomatology is usually insidious, however, acute exacerbations have been reported, especially during pregnancy presumably due to increased vascular volume and hormonal influences on vascular tone. ${ }^{11}$

The nonparasellar lesions have had variable presentations including facial nerve impingement through erosion into 
Table 1: Clinical features of cavernous angiomas

\begin{tabular}{lll}
\hline $\begin{array}{l}\text { Lesion } \\
\text { cavernous angioma (intraaxial) } \\
\text { cavernous angioma }\end{array}$ & $\begin{array}{l}\text { Presentation } \\
\text { most are silent, minority hemorrhage } \\
\text { ocular symptoms }\end{array}$ & $\begin{array}{l}\text { Age/sex/race/familial trends } \\
\text { some autosomal dominant }\end{array}$ \\
$\begin{array}{l}\text { cavernous angioma } \\
\quad \text { dural, middle fossa, nonparasellar) }\end{array}$ & cranial nerve VII lesions, seizures & $\begin{array}{c}\text { yr peak age range, female, higher } \\
\text { incidence in Japanese }\end{array}$ \\
$\begin{array}{l}\text { cavernous angioma } \\
\quad \text { dural, non-middle fossa) }\end{array}$ & headache, seizures, local compressive symptoms & none \\
& & none \\
\end{tabular}

Table 2: Radiographic features of vascular malformations

\begin{tabular}{|c|c|c|c|c|}
\hline $\begin{array}{l}\text { Lesion } \\
\text { cavernous angioma } \\
\text { (intra-axial) }\end{array}$ & $\begin{array}{l}\text { Location } \\
\text { mostly supratentorial, } \\
\text { superficial }\end{array}$ & $\begin{array}{l}\text { CT } \\
\text { iso- to hyperdense, } \\
\text { variable calcification }\end{array}$ & $\begin{array}{l}\text { MRI } \\
\text { variable core of subacute } \\
\text { to chronic blood, rim of } \\
\text { low signal }\end{array}$ & $\begin{array}{l}\text { Enhancement } \\
\text { minimal to no } \\
\text { enhancement }\end{array}$ \\
\hline $\begin{array}{l}\text { cavernous angioma } \\
\text { (extra-axial) }\end{array}$ & $\begin{array}{l}\text { mostly parasellar, } \\
\text { middle fossa }\end{array}$ & $\begin{array}{l}\text { variable density, variable } \\
\text { calcification, may alter } \\
\text { underlying bone }\end{array}$ & $\begin{array}{l}\text { heterogeneous usually } \\
\text { low signal } \mathrm{T} 1 \text {, heterogeneous } \\
\mathrm{T} 2 \text { with prolongation }\end{array}$ & $\begin{array}{l}\text { intense } \\
\text { enhancement }\end{array}$ \\
\hline venous angioma & $\begin{array}{l}65 \% \text { supratentorial } \\
40 \% \text { frontal }\end{array}$ & normal non-contrast exam & tubular vessels with "caput" & $\begin{array}{l}\text { enhancement of tuft } \\
\text { of veins and } \\
\text { abnormal draining vein }\end{array}$ \\
\hline telangiectasia & ubiquitous & $\begin{array}{l}\text { inconspicuous, may show } \\
\text { hemorrhage }\end{array}$ & $\begin{array}{l}\text { usually normal } \mathrm{T} 1 \text { and } \mathrm{T} 2 \text {, } \\
\text { with occasional } \mathrm{T} 2 \text { or gradient } \\
\text { echo hypointensity }\end{array}$ & $\begin{array}{l}\text { minimal homogeneous } \\
\text { enhancement }\end{array}$ \\
\hline
\end{tabular}

temporal bone, ${ }^{12}$ and cortical irritation resulting in seizures, as in the present case.

Dural cavernomas arising outside the middle fossa have a wide age spectrum from neonates to the elderly with no gender predisposition. ${ }^{5}$ In the review by Lewis et al, ${ }^{1}$ nonspecific headache was the most common initial presentation $(75 \%, 9$ of 12 patients) and seizures occured in $22 \%$ (4 of 18). Isolated cases of symptomatology due to focal compression are encountered, especially in the posterior fossa (ataxia, hearing loss). ${ }^{12}$ There have been no reports of spontaneous hemorrhage with lesions outside the middle fossa. ${ }^{5}$

Magnetic resonance is the imaging study of choice for parenchymal cavernomas. ${ }^{7}$ The characteristic and diagnostic imaging findings include a heterogenous core composed of various stages of hemorrhage, a peripheral rim of low signal intensity representing hemosiderin and no adjacent edema. A CT may show a slightly hyperdense lesion, with or without calcification and minimal enhancement. ${ }^{6,7}$ Willinsky et al ${ }^{13}$ recently reviewed the spectrum of radiographic features of intraaxial cavernomas.

The imaging findings of dural cavernomas are substantially different (Table 2). The MRI diagnostic basis of parenchymal lesions depends on the presence of subacute and chronic hemorrhage both centrally and peripherally. These findings do not appear to exist in dural lesions. ${ }^{5,12,14}$ The MRI examinations demonstrate an extra-axial dural-based lesion with heterogeneous $\mathrm{T} 1$ and $\mathrm{T} 2$ findings. T2 hyperintensity to brain is typical in contrast to most (but not all) meningiomas. The T2 prolongation in cavernous angiomas is believed to be secondary to slow flow in the vascular spaces. ${ }^{8}$ The lesions enhance intensely in a homogeneous or heterogeneous pattern. The underlying bone can also be affected with thickening and erosion. ${ }^{5,8}$ Computerized tomography shows an enhancing extraaxial lesion of varied density. Tumour calcification may be present. Bony invasion is unusual, with only two previously reported examples to date. ${ }^{15,16}$

Angiography reveals a vascular peripheral lesion. Dural cavernomas outside the middle fossa can show a tumour blush, pooling in the venous phase or, rarely, may appear avascular. Lesions of the middle fossa show intense enhancement with possible identification of an external carotid (middle meningeal) or internal carotid (meningo-hypophyseal) arterial supply. The 

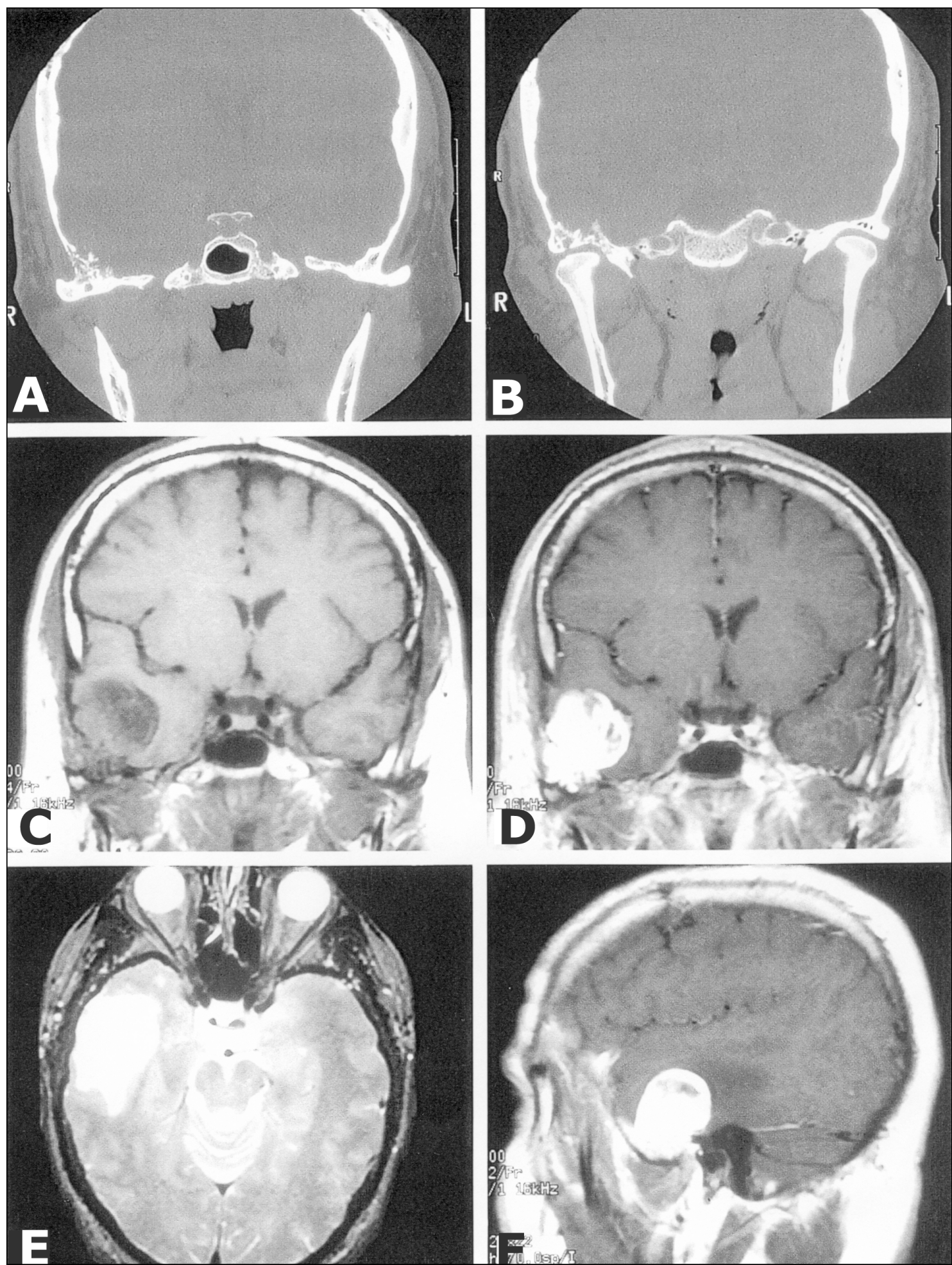

Figure 1: Preoperative MRI demonstrates a $3 \mathrm{~cm}$ mass arising from the floor of the right middle cranial fossa:

a) and $\boldsymbol{b})$ The CT scans show an irregularly destructive lesion of the floor and inferolateral wall of the right middle cranial fossa with cortical breakthrough both into the middle fossa as well as into the temporomandibular joint,

c) and d) T1 weighted images, pre and post gadolinium enhancement respectively revealing mixed signal intensities and irregular enhancement,

e) T2 weighted image demonstrating lesional hyperintensity to brain and perilesional edema,

f) T1 weighted image, post gadolinium, parasagittal view. 
Table 3: Pathological features of vascular malformations

\begin{tabular}{lll}
\hline Lesion & Vessels & Intervening CNS tissue \\
cavernous angioma (intra-axial) & sinusoidal venules, capillaries & no / negligible \\
cavernous angioma (extra-axial) & sinusoidal venules, capillaries & no / negligible \\
arteriovenous malformation & arteries, capillaries, veins, arterialized veins & yes \\
venous angioma & veins & yes \\
telangiectasia & capillaries & yes
\end{tabular}

cavernous internal carotid and middle cerebral artery can show evidence of displacement secondary to the mass effect of the adjacent lesion. . $^{5,11}$

Grossly, the lesions are rubbery firm and have a capsule that is contiguous with adjacent dura. The internal architecture is typically lobulated and spongy in appearance with a reddishbrown colour in the fresh state. Microscopic examination reveals a lesion comprised almost entirely of vascular elements, all of which are sinusoidal thin-walled vessels lined by a single endothelial layer (Figure 2a). The vessels are separated by a minimal fibrous interstitium which is sparsely populated by benign spindle cells (Figure 2b). This architecture distinguishes the cavernous angioma from other vascular malformations (Table 3) and vascular tumours. The endothelial elements are positive for immunohistochemical markers Factor 8 and Ulex europius (Figure $2 \mathrm{c}$ and $2 \mathrm{~d}$ ), and negative for a marker of meningothelial cells (epithelial membrane antigen). Histologic evidence of anaplasia has not been described.

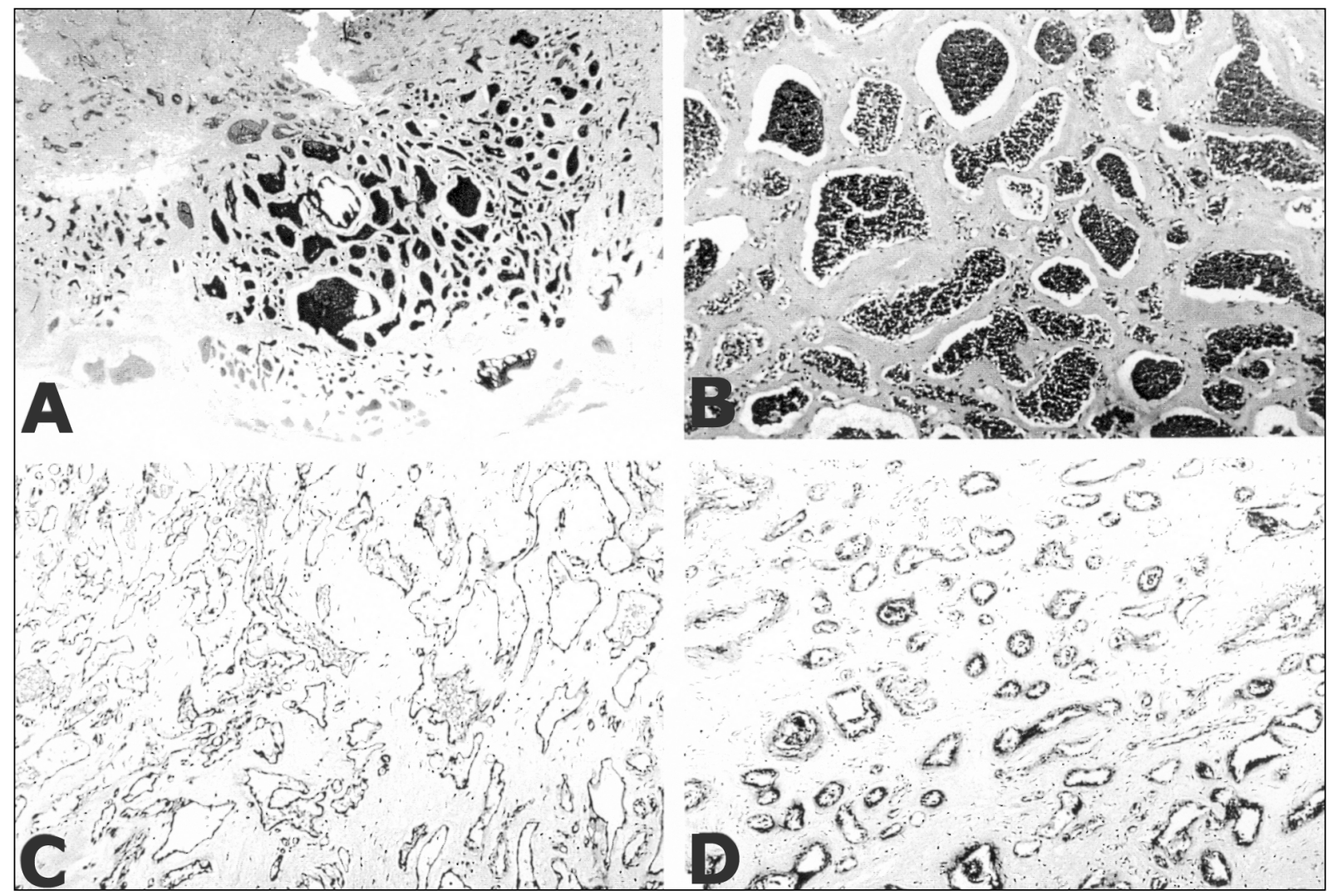

Figure 2: Histology and immunohistochemistry of the resected tumour:

a) and b) Hypocellular, vascular lesion composed of tightly arranged small calibre sinusoidal venous channels, (H\&E, $x 5$ and $x 30$ respectively),

c) Vascular elements bind the lectin Ulex europius, $(x 30)$,

d) Vascular elements express Factor VIII, (anti-Factor VIII, x30). 
The imaging characteristics of dural cavernomas are usually not substantially different from meningiomas, the most likely preoperative diagnosis in such cases. Occasionally, the degree and pattern of calvarial involvement can suggest a more aggressive lesion, at which time dural cavernomas should also be considered..$^{5,8}$

Extra-axial cavernous angiomas can prove to be diagnostically problematic. Radiographically, they are at times indistinguishable from meningiomas, the most common preoperative diagnosis. The decision to excise these lesions is usually made without knowledge of their final diagnosis; hence the decision to excise is based upon symptoms akin to a meningioma in the same region, or the rare occurrence of hemorrhage. ${ }^{5}$ As a result, angiomas should be included in the differential diagnosis of extra-axial lesions in the middle cranial fossa, especially in a parasellar location. Many of the parasellar examples could only be partially excised as a result of severe intraoperative hemorrhage. Those not in the parasellar region have been almost uniformily amenable to complete resection. Given their benign histological nature, excision is presumed to be curative but the role of conservative management has not been assessed.

Cases involving the cavernous sinus have a high operative mortality and morbidity with several deaths attributed to extensive intraoperative blood loss. Preoperative irradiation ${ }^{17}$ and embolization have been proposed to reduce the likelihood of excessive bleeding. A more recent study suggests that a revised intraoperative approach would also reduce the risk of catastrophic blood loss. ${ }^{18}$ Lesions not involving the parasellar/cavernous sinus region have been associated with low morbidity and mortality.

Those lesions that have been completely excised should pose no subsequent risk of recurrence. Even those that are incompletely excised would not be expected to enlarge as they do not appear to harbour any neoplastic potential. They may, however, pose a small risk of hemorrhage. ${ }^{5}$ Little follow-up data are available on the few reported cases in the literature and their natural history under conservative management is unknown.

In summary, this rare entity poses a diagnostic challenge at times, when its radiographic features do not distinguish it from other considerations. Extra-axial lesions of the middle cranial fossa with T2 hyperintensity and enhancement should be approached with cavernous angioma in the differential and with particular caution afforded those in a parasellar location. The present case also demonstrates the potential for bony erosion by this entity which may give the misleading impression of a more anaplastic tumour. The natural history of dural angiomas is poorly understood, and lesions with tolerable symptomatology may be best managed in a conservative fashion and so add to our understanding of their biological potential.

\section{REFERENCES}

1. Lewis AI, Tew JMJ, Payner TD, Yeh HS. Dural cavernous angiomas outside the middle cranial fossa: a report of two cases. Neurosurgery 1994;35(3):498-504.

2. Vogler R, Castillo M. Dural cavernous angioma: MR features. AJNR Am J Neuroradiol 1995;16(4):773-775.

3. Perry JR, Tucker WS, Chui M, Bilbao JM. Dural cavernous hemangioma: an under-recognized lesion mimicking meningioma. Can J Neurol Sci 1993;20(3):230-233.

4. Namba S. Extracerebral cavernous hemangioma of the middle cranial fossa. Surg Neurol 1983;19(4):379-388.

5. Atlas SW (Ed). Magnetic Resonance Imaging of the Brain and Spine. 2 ed. Philadelphia: Lippincott-Raven; 1996.

6. Isla A, Roda JM, Alvarez F, et al. Intracranial cavernous angioma in the dura. Neurosurgery 1989;25(4):657-659.

7. Linskey ME, Sekhar LN. Cavernous sinus hemangiomas: a series, a review, and an hypothesis. Neurosurgery 1992;30(1):101-108.

8. Momoshima S, Shiga $\mathrm{H}$, Yuasa $\mathrm{Y}$, et al. MR findings in extracerebral cavernous angiomas of the middle cranial fossa: report of two cases and review of the literature. AJNR Am J Neuroradiol 1991;12(4):756-760.

9. Morello A, Tumbiolo A, Pinto G, Lo DB. Cavernous angioma of the spinal dura. J Neurosurg Sci 1991;35(1):31-35.

10. Porter PJ, Willinsky RA, Harper W, Wallace MC. Cerebral cavernous malformations: natural history and prognosis after clinical deterioration with or without hemorrhage. J Neurosurg 1997;87(2):190-197.

11. Mori K, Handa H, Gi H. Cavernomas in the middle fossa. Surg Neurol 1980;14(1):21-31.

12. Osborne A, Tong K. Handbook of Neuroradiology: Brain \& Skull. 2 ed. Mosby-Yearbook Inc.; 1996.

13. Willinsky RA, Harper W, Wallace MC, et al. Follow-up MR of intracranial cavernomas, the relationship between hemorrhage events and morphology. Interventional Neuroradiology 1996;2:127-135.

14. Osborn AG, Patterson AS (Ed). Diagnostic Neuroradiology. St. Louis, Missouri: Mosby-Year Book, Inc.; 1994.

15. Okada J, Hara M, Takeuchi K. Dural haemangioma with extracranial component. Acta Neurochir (Wien ) 1977;36(12):111-115.

16. Rushton AW, Ng HK, Metreweli C. Dural cavernous haemangioma with bony infiltration. Clin Radiol 1999;54(6):406-408.

17. Pozzati E, Giuliani G, Ferracini R, Gaist G. Facial nerve palsy secondary to a dural cavernous angioma of the middle cranial fossa eroding the tegmen tympani. Neurosurgery 1988;23(2):245-247.

18. Revuelta R, Teixeira F, Rojas R, et al. Cavernous hemangiomas of the dura mater at the convexity. Report of a case and therapeutical considerations. Neurosurg Rev 1994;17(4):309-311. 